\title{
A New Grease-Pocket Shape to Extend the Service Life of Grease
}

\author{
Sumiko Hibino $^{1)^{*}}$, Tetsuya Hosoya ${ }^{1)}$, Kazuo Nakamura ${ }^{1)}$, \\ Koichi Matsuoka ${ }^{2}$, Takashi Nagayama ${ }^{3)}$, Minoru Kitamura ${ }^{3)}$ and Teruhiko Sunohara ${ }^{3)}$ \\ ${ }^{1)}$ Laboratory of Lubricating Materials, Materials Technology Division, Railway Technical Research Institute \\ 2-8-38 Hikaricho, Kokubunji, Tokyo 185-8540, Japan \\ ${ }^{2)}$ Transportation Vehicle Systems Engineering Dept., Transportation Systems Div., Toshiba Corporation \\ 1-1-1 Shibaura, Minato-ku, Tokyo 105-8001, Japan \\ ${ }^{3)}$ Development \& Designing Group 2, Transportation Systems Dept., Fuchu Complex, Toshiba Corporation \\ 1 Toshiba-cho, Fuchu, Tokyo 183-8511, Japan \\ *Corresponding author: nabe@rtri.or.jp
}

( Manuscript received 8 January 2008; accepted 19 February 2008; published 15 April 2008 )

( Presented at JAST Tribology Conference Saga, September 2007 )

\begin{abstract}
The peroidicity of motor disassembly for maintenance is currently determined by the durability of the sealed grease they contain. The lifetime of this grease is the shortest of all the motor's bearing parts and materials, and therefore needs to be made longer. For this purpose, therefore, the authors discussed the shape of the grease pocket, and concluded that the efficiency of lubrication depends on the shape of the pocket and the relative position between pockets and the bearing, which should be appropriately modified. In this report, the authors performed laboratory testing with full-scale grease pocket models of refined and conventional shapes to compare the service lives and determine the effects of improvement.
\end{abstract}

Keywords: grease, grease pocket, rolling bearing, tracer, tribology, traction motor

\section{Introduction}

Induction traction motors have recently been replacing DC motors in railway rolling stock. This has necessitated changes to the conventional maintenance procedure, since maintenance for the commutators and brushes of conventional DC motors (whose periodicities are shorter than those of other parts and materials) is no longer required. Instead, the disassembly inspection cycle depends on the durability of bearings, and it is therefore essential to extend the service life of the lubricating grease that represents the least durable material used with them.

For lubrication of the bearings in induction motors, bearing covers located on both sides of the bearings have been provided with hollows known as grease pockets (GP), which are filled with grease in addition to the bearing's inner space to improve a lubricating effect.

The authors performed laboratory tests using three types of currently used induction motor with typical hollows of different shapes in the outer cover. They compared the behavior of the grease base oil in each, and showed that the grease's service life is likely to be extended by refining the properties of grease pockets such as their depth or the volume of grease they contain ${ }^{1)}$.
In addition, the authors studied grease pocket characteristics that may affect the behaviour of the base oil to find the optimal shape in terms of the base oil supplied from the grease contained in the pockets. From the results, they developed guidelines to determine the shape of grease pockets ${ }^{2}$.

This report first presents the results of durability testing with the improved models, as well as those of the heat and radiation performance around the bearings with the improved models applied in an induction motor.

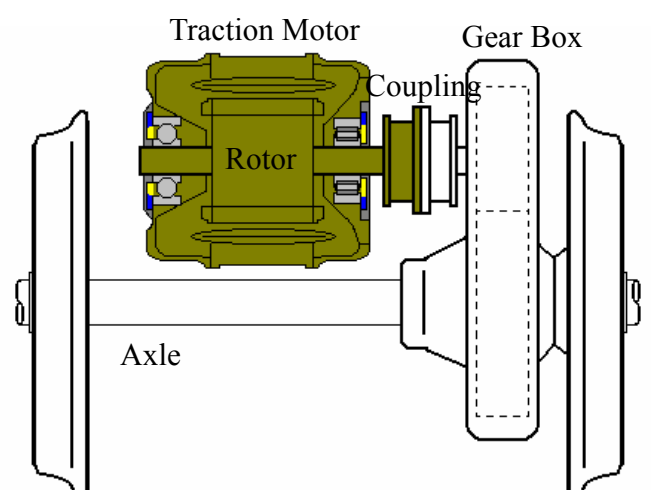

Fig.1 A typical driving device structure 


\section{Induction motor and bearing structure}

Figure 1 exemplifies a typical driving device structure. An induction motor is equipped with a

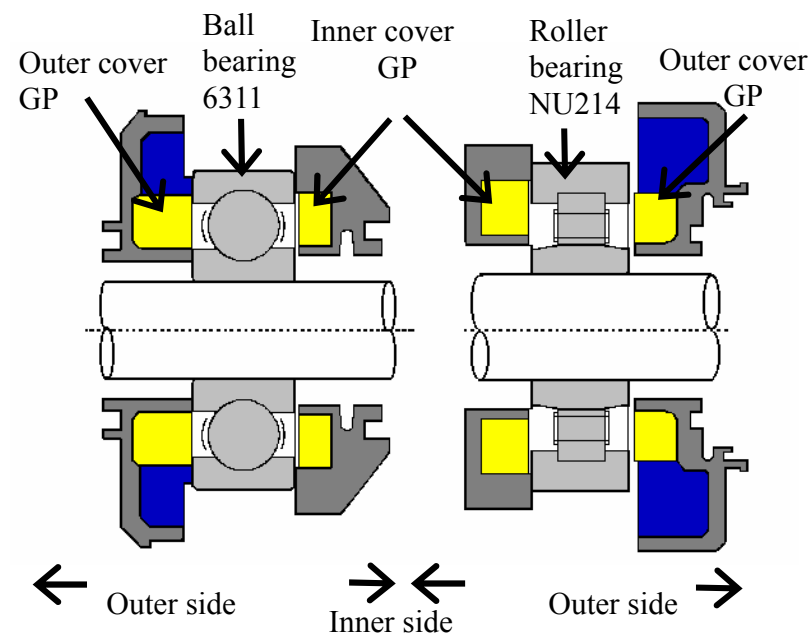

Fig.2 Sectional view of bearings

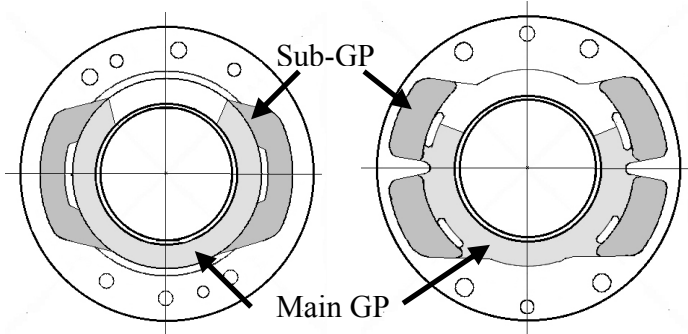

(A) Conventional type
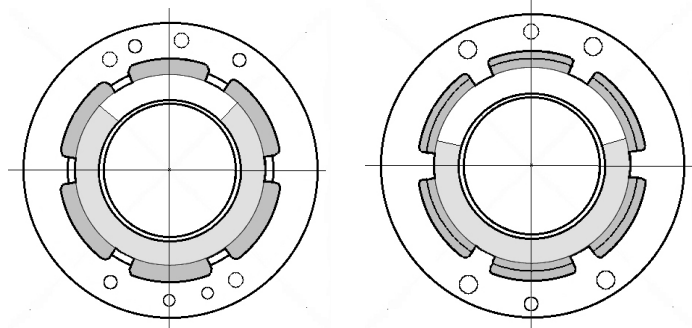

(B) Improved models \#1
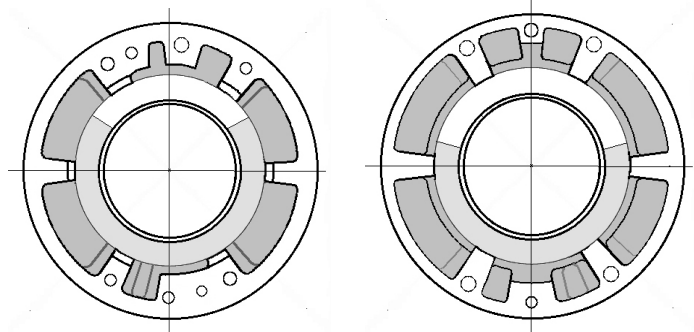

(C) Improved models \#2

MT204 type

MT205 type

Fig.3 Comparison of conventional and improved models (examples of ball bearing - the shaded areas contain grease $)^{2)}$ cylindrical roller bearing on the gear unit side and a deep groove ball bearing on the opposite side, which act as support bearings for the internal rotor. Grease is enclosed to lubricate them.

Figure 2 shows a sectional view of the bearings. Both are fitted with covers on either side (inner and outer) and each has a grease pocket (GP).

\section{Analytical method}

\subsection{Grease test specimens}

During the studies, the lithium-complex grease currently used for vehicle motors was used.

\subsection{Analytical method for grease deterioration}

During the life comparison tests, we sampled the grease specimens on the cages of bearings to analyze the time deterioration related to a running distance of $600,000 \mathrm{~km}$. After the motor application tests, we also sampled the grease specimens and analyzed oxidation deterioration.

The oxidation rate is the criterion for oxidation deterioration, with larger values indicating more oxidation. The authors investigated the infrared absorption spectra of the specimen and determined the absorption intensity caused by the oxidation deterioration products. They used oleic acid as the model substance, and converted the rate of deterioration (estimated by the acid products) to the amount of oleic acid.

\section{Improvement of GP structure and oil circulation testing $^{2)}$}

Several different types of outer-cover hollow shape are used for the types of motors installed on vehicles (Figure $3(\mathrm{~A})$ ). They are usually equipped with an annular grease pocket (the main GP), which is located facing the rolling elements of the bearings. In addition, they are equipped with outer grease pockets (sub-GPs) on either side of the main GP in many cases. Each type is fitted with an inner cover with a main GP only.

In previous studies ${ }^{2}$, the authors have shown guidelines to design an advanced GP shape that causes the base oil to circulate more than with the conventional model by (1) increasing the depth of the annular grease pocket and (2) widening the oil paths between the main GP and sub-GPs (the oil path).

Accordingly, based on the MT204 and MT205 traction motors currently in service (Figure 3 (A)), full-scale working models of GPs were designed and manufactured with larger contact areas but an unchanged GP volume (Figure 3 (B)). Secondly, full-scale GP models were designed with larger contact areas and sub-GPs with as much volume as possible (this is limited by the relative locations of bolt holes and the opening for ventilation in current motors) (Figure $3(\mathrm{C})$ ). 


\section{Effect on elongation of grease service life}

To confirm the effect on the elongation of grease service life, bearing rotation tests with full scale models were performed for this report to compare grease service life between using the conventional grease pocket and the improved one (referred to below as life comparison tests).

\subsection{Test conditions}

The authors adopted MT205 models for the life comparison tests, using those shown in the right-hand column of (A) and (C) for outer covers and the conventional annular shape for inner covers. The test conditions were as shown in Table 1. The rotation was finished only when the grease had reached the end of its service life.

\subsection{Test method of grease enclosed}

Table 2 shows the amounts of grease enclosed. To clarify the effect of different GP shapes, grease was filled each of the conventional and improved GP to the brims. The amount of grease in the bearings was unified to 30 percent of their inner volume ratio. In addition, for the conventional model, the total amount was calculated by that indicated in the drawings, and conformed to the capacity of the GP currently used.

\subsection{Judgment of grease service life}

Grease was judged to have reached the end of its service life during the tests when bearing failure occurred and the test could not be continued. In ASTM D1741, the earliest positive evidence of bearing distress was used to determine the time of failure. This may be one of the following:

- Stalling of the motor during operation

- Stalling of the motor when attempting to start after shutdown

Table 1 Rotation test conditions

\begin{tabular}{|c|c|c|c|c|c|}
\hline \multicolumn{2}{|c|}{$\begin{array}{c}\text { Temperature } \\
\text { (degrees C) }\end{array}$} & $\begin{array}{c}\text { Rotation } \\
\text { speed } \\
\left(\mathrm{min}^{-1}\right)\end{array}$ & $\begin{array}{c}\text { Radial } \\
\text { load } \\
(\mathrm{N})\end{array}$ & $\begin{array}{c}\text { Axial } \\
\text { Load } \\
(\mathrm{N})\end{array}$ & $\begin{array}{c}\text { Rotating } \\
\text { cycle } \\
(\mathrm{h})\end{array}$ \\
\cline { 1 - 5 } $\begin{array}{c}\text { Ball } \\
\text { bearing }\end{array}$ & $\begin{array}{c}\text { Roller } \\
\text { bearing }\end{array}$ & 5,700 & 800 & 0 & $\begin{array}{c}\text { rotation } \\
(100 \mathrm{~h}) \\
\text { suspension } \\
(2 \mathrm{~h})\end{array}$ \\
\hline 90 & 95 & 5, & & &
\end{tabular}

Table 2 Grease amount enclosed for life comparison tests $(\mathrm{g})$

\begin{tabular}{|c|c|c|c|c|c|}
\hline \multicolumn{2}{|c|}{ Parts } & \multicolumn{2}{|c|}{$\begin{array}{l}\text { Outer } \\
\text { cover }\end{array}$} & \multirow{2}{*}{$\begin{array}{c}\text { Bearing } \\
\begin{array}{l}\text { Inner } \\
\text { space }\end{array}\end{array}$} & \multirow{2}{*}{$\begin{array}{c}\begin{array}{c}\text { Inner } \\
\text { cover }\end{array} \\
\text { Main } \\
\text { GP }\end{array}$} \\
\hline & & $\begin{array}{l}\text { Main } \\
\text { GP }\end{array}$ & $\begin{array}{c}\text { Sub } \\
\text {-GP } \\
\text { (total) }\end{array}$ & & \\
\hline \multirow{2}{*}{$\begin{array}{c}\text { Ball } \\
\text { bearing }\end{array}$} & (A) & \multirow{2}{*}{35.0} & 36.0 & \multirow{2}{*}{20.0} & \multirow{2}{*}{38.0} \\
\hline & (C) & & 77.5 & & \\
\hline \multirow{2}{*}{$\begin{array}{c}\text { Roller } \\
\text { Bearing }\end{array}$} & (A) & \multirow{2}{*}{48.5} & 60.0 & \multirow{2}{*}{13.0} & \multirow{2}{*}{39.5} \\
\hline & (C) & & 101.5 & & \\
\hline
\end{tabular}

- A temperature rise of 10 degrees $\mathrm{C}$ above the control temperature

- A distinct increase in noise level persisting for 10 minutes, either intermittently or continuously.

The authors made judgment based on these criteria.

\subsection{Test results}

\subsubsection{Comparison of grease service life}

We judged the ball bearing in the conventional model to have reached the end of its lifetime after accumulated rotation equivalent to $1,467,000 \mathrm{~km}$ of running, as unusually large vibration and a temperature rise of 25 degrees $\mathrm{C}$ in the inner ring of the bearing meant that rotation could not continue. Investigation of the disassembled ball bearing after the test showed that progressive wear on the ball/cage interface and an increase in the gap of the cage had caused the cage to rotate irregularly and scrape against the inner and outer rings, resulting in a rapid shift in temperature.

The roller bearing in the conventional model was judged to have expired by the motor stalling when attempting to start after shutdown at an accumulated rotation count corresponding to 2,634,000 km of running. After assembly, the bearing locked and could not rotate. Investigation of the bearing revealed that wear had progressed in a similar way to that of the ball bearing. The grease had undergone oxidation deterioration as a result of the long duration of its use, which seems to have caused the bearing to lock.

For the improved models, the rotation tests continued until an accumulated rotation corresponding to 3,600,000 $\mathrm{km}$ of running (Figure 4). That is, lifetime comparison suggests that the improved models will last as about twice as long for ball bearings and about 1.3 times as long for roller bearings. Practically for maintenance, it is necessary to disassemble induction motors before the failure of the ball bearings which have shorter lifetimes; the periodicity of motor disassembly is expected to be extended to double when the improved GP is applied.

\subsubsection{Change in appearance of grease in the GP}

We observed the appearance of the grease surface in the GP for durations of $600,000,1,200,000,1,800,000$, $2,400,000$ and $3,000,000 \mathrm{~km}$. With increased running durations, the color changed from pale yellow to dark

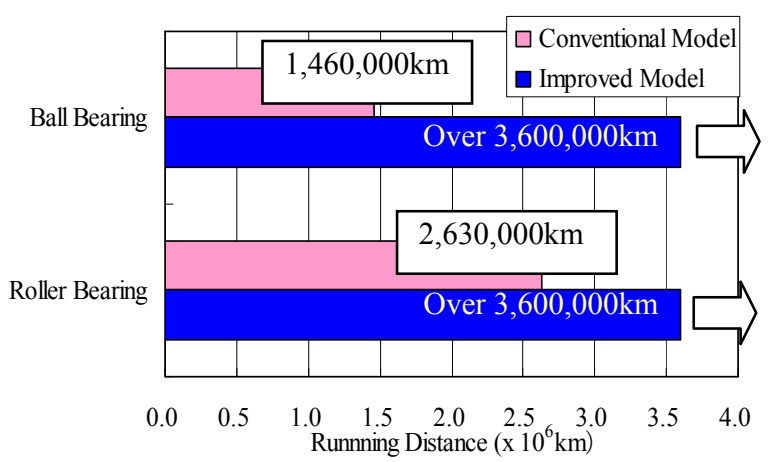

Fig. 4 Comparison of life durations 


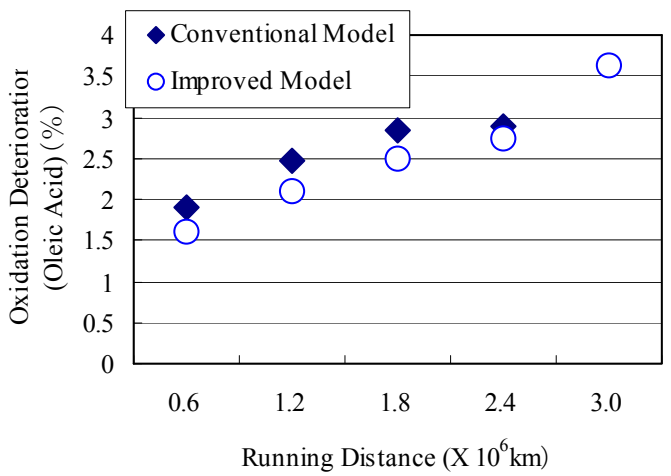

Fig.5 Oxidation deterioration for life comparison test

brown, and the grease dried and chapped on the surface. However, there was no specific point at which the change in appearance indicated that the grease had reached the end of its lifetime.

\subsubsection{Alteration in oxidation deterioration rate}

To investigate the oxidation deterioration rate with the increase in test duration, the authors interrupted the running and sampled the grease on the cage at a duration of $600,000 \mathrm{~km}$. As the test bearing was running continuously, we sampled the grease from only one of the sixteen pillars in each case to minimize the influence on the running. New grease was not added to compensate the decreased quantity. The transition in the oxidation deterioration rate at a running duration of $600,000 \mathrm{~km}$ is shown in Figure 5. It can be seen that the grease in the bearings gradually oxidized.

In comparison of the conventional and improved models, the oxidation rate for the latter was less than that of the former over the test duration. The rate at 1,800,000 $\mathrm{km}$ using the improved model was equivalent to the rate at $1,200,000 \mathrm{~km}$ using the conventional model.

As the grease enclosure conditions were uniform for each model at the sampling location (i.e. the bearings), the difference seems to have been caused by the amount of oil flowing to the bearings from the GP of the outer and inner covers.

\section{Motor application tests}

\subsection{Improvement of structure for insulated bearings}

For the traction motors used in vehicles, insulated bearings are applied to prevent electrical pitting. Two types of insulating materials are used; ceramics (mainly used for Shinkansen trains), and PPS (polyphenylene-sulfide) polymer (mainly used for conventional trains). In the improved GP, the brace used to bank up the outer rings of the bearings is minimized to widen the oil paths, which means that it may impair the insulating material. This is especially true with PPS, which is mechanically weak compared with ceramics and metals when the surface pressure becomes relatively higher than the compressed limit. Then, based on the models for life comparison testing, which are applicable to ceramic insulated bearings, the authors designed a new
GP model considering the strength of the PPS material and the limit of surface pressure from past proven results on the structure of practical motors (Figure 6).

\subsection{Motor application test}

We carried out a test using an identical traction motor to compare the newly designed GP for PPS bearings with the conventional GP under the same conditions. The tests investigated whether the heat and radiation performance of the motor is within the same range as the conventional model with a space left unfilled at the top of the main GP as the GP for PPS bearings with grease fully packed.

With the motor rotating under loaded conditions, the heat generated from the bearings could not be discriminated from that generated by the rotor, which was relatively high. The authors first tried to determine the heat generated by the bearings in a high-speed no-load test. After that, the models were subjected to rated load testing with the same conditions as thermal performance testing by the traction motor manufacturer. After the test, we compared the thermal conditions with those of current traction motors.

\subsubsection{High-speed no-load test $\left(6120 \mathrm{~min}^{-1}\right)$}

The elevated levels of the saturated temperature measured at the outer rings of bearings using the GP model for PPS were $24 \mathrm{~K}$ higher for the ball bearing and $3 \mathrm{~K}$ higher for the roller bearing than the conventional model under a cooling airflow volume of $4 \mathrm{~m}^{3} / \mathrm{min}$. The difference seemed to be caused by the existence of the space in the main GP.

Moreover, there was no difference in the elevated levels of the saturated temperature under a cooling airflow volume of $14 \mathrm{~m}^{3} / \mathrm{min}$.

\subsubsection{Rated load test (2947 $\mathrm{min}^{-1}, 1430 \mathrm{~V}, 106 \mathrm{~A}$ )}

The elevated levels of the saturated temperature measured at the outer rings using the GP model for PPS were within the same range as those of the conventional one. This seemed to be caused by the rated cooling air condition of $20 \mathrm{~m}^{3} / \mathrm{min}$, which was sufficiently strong. Consequently, its thermal performance is acceptable as compared with current motors.

\section{Discussions}

7.1. Grease amount comparison for life comparison testing

In general, it is advantageous to enclose as much

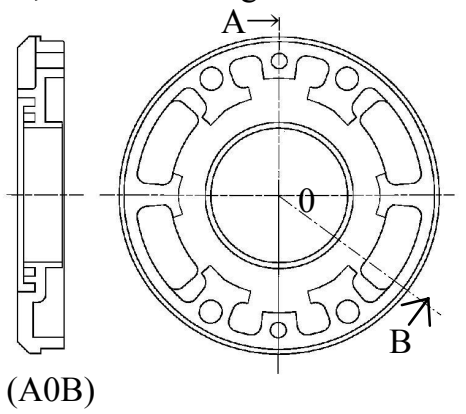

Fig.6 The new grease pocket model for PPS 
Table 3 Grease amount comparison

\begin{tabular}{|c|c|c|}
\hline & $\begin{array}{c}\text { Ball } \\
\text { bearing }\end{array}$ & $\begin{array}{c}\text { Roller } \\
\text { bearing }\end{array}$ \\
\hline $\begin{array}{c}\text { Life comparison tests, conventional } \\
\text { model (fully-packed) }\end{array}$ & $129 \mathrm{~g}$ & $161 \mathrm{~g}$ \\
\hline $\begin{array}{c}\text { (Reference) Conventional model } \\
\text { (with a space, indicated on the drawing) }\end{array}$ & $104 \mathrm{~g}$ & $131 \mathrm{~g}$ \\
\hline $\begin{array}{c}\text { Life comparison tests, improved model } \\
\text { for ceramics (fully-packed) }\end{array}$ & $170.5 \mathrm{~g}$ & $202.5 \mathrm{~g}$ \\
\hline $\begin{array}{c}\text { (Reference) Ratio for models } \\
\text { improved model / conventional model } \\
\text { with a space }\end{array}$ & $164 \%$ & $155 \%$ \\
\hline $\begin{array}{c}\text { Ratio for fully-packed models } \\
\text { improved model / conventional model }\end{array}$ & $132 \%$ & $126 \%$ \\
\hline
\end{tabular}

Table 4 Contact areas of main GP and sub-GPs

\begin{tabular}{|c|c|c|}
\hline & $\begin{array}{c}\text { Ball } \\
\text { bearing }\end{array}$ & $\begin{array}{c}\text { Roller } \\
\text { bearing }\end{array}$ \\
\hline $\begin{array}{c}\text { Life comparison tests, conventional } \\
\text { model (fully-packed) }\end{array}$ & $\begin{array}{c}623 \\
\mathrm{~mm}^{2}\end{array}$ & $\begin{array}{c}1058 \\
\mathrm{~mm}^{2}\end{array}$ \\
\hline $\begin{array}{c}\text { (Reference) Conventional model (with a } \\
\text { space, indicated on the drawing) }\end{array}$ & $\begin{array}{c}450 \\
\mathrm{~mm}^{2}\end{array}$ & $\begin{array}{c}1058 \\
\mathrm{~mm}^{2}\end{array}$ \\
\hline $\begin{array}{c}\text { Life comparison tests, improved model } \\
\text { for ceramics (fully-packed) }\end{array}$ & $\begin{array}{c}2540 \\
\mathrm{~mm}^{2}\end{array}$ & $\begin{array}{c}2955 \\
\mathrm{~mm}^{2}\end{array}$ \\
\hline Ratio for fully-packed models & $408 \%$ & $279 \%$ \\
improved model / conventional model & & \\
\hline $\begin{array}{c}\text { Motor application test, improved model } \\
\text { for PPS }\end{array}$ & $\begin{array}{c}2014 \\
\mathrm{~mm}^{2}\end{array}$ & $\begin{array}{c}2638 \\
\mathrm{~mm}\end{array}$ \\
\hline $\begin{array}{c}\text { Ratio for fully-packed models } \\
\text { model for PPS / for ceramics }\end{array}$ & $79 \%$ & $89 \%$ \\
\hline
\end{tabular}

grease as possible for lubrication purposes. To compare the grease amount for life comparison testing before and after the improvements, the volumes are as shown in Table 2. The grease amounts enclosed are $20 \mathrm{~g}$ for ball bearings and $13 \mathrm{~g}$ for roller bearings. The increase in total amount differs among the models depending on structural restrictions, and approximately 1.3 times as much grease can be put in the improved models as the conventional models under the conditions of life comparison testing (Table 3). Comparing the grease amount in the bearing parts of current motors (with a space at the top of the main GP as indicated on the drawings) to the improved ones, the increase is approximately 1.6 times as shown in Table 3. The increase between the models for ball bearings and roller bearings is approximately in the same range.

7.2. Comparison of the contact area between main and sub-GPs

Table 4 gives a comparison of the contact areas among the models used in this report, and shows that they vary widely.

For life comparison testing, comparison between the models of the ball bearings and of the roller bearings shows that the area for the former increased more than that of the latter. Considering that the increase in the grease amount is almost equivalent, the difference in the contact area increase results in the elongation of grease service life for the ball bearing. Conversely, if both the increase in the grease amount and the contact areas are almost equivalent, it can be concluded that the ball bearings are affected more by improvement of the GP. However, discussion of whether the ball or the roller bearing is affected more cannot be made because the increase in contact area differs so much.

Previous reports ${ }^{2}$ have demonstrated that oil circulation depends greatly on the contact area. For motor application testing, since the model for PPS has a smaller area than that of the model for ceramics, an improvement effect from modification of the GP shape following the guidelines is anticipated in the model for ceramics.

\section{Conclusions}

1. It was evident that simply modifying the shape of the GP in the outer covers of traction motors produces an elongation effect on the lubrication life of bearings. In general, it is advantageous to enclose as much grease as possible; however, it was revealed that not only the volume but also the hollow shapes that contain the grease have a satisfactory effect on elongating the grease service life.

2. We performed motor application tests to confirm that thermal performance is efficient when the improved models are used in current motors. According to high-speed testing, the elevated levels of saturated temperature using the GP model for PPS are higher than those for conventional models. This is contrary to the situation under a rating air-volume condition, where the difference in the elevated levels of the saturated temperature reduced.

3. A model for PPS can be obtained by controlling the surface pressure on the outer ring of the bearing considering the strength of the PPS material; however, an improvement effect from modifying the GP shape following the guidelines can be strongly expected in the model for ceramics.

\section{Acknowledgement:}

The RTRI and TOSHIBA Corporation carried out the studies in this report in collaborative investigation. The authors wish to express appreciation for the mutual cooperation, assistance and suggestions involved in the study.

\section{References}

[1] Hibino, S., Hosoya, T., Sone, Y., Nakamura, K. and Suzuki, M., "Lubricating Motion of Grease in the Bearing of Induction Motor," Proc. Int. Tribol. Conf., Nagasaki 2000, 1, 2001, 1401-1405.

[2] Hibino, S. and Suzuki, M., "A Proposal of Grease Pocket Structure in Consideration of Base Oil Migration," J. Japn. Soc. Tribologists, 50, 1, 2005, 39-46. 